\title{
Phytomelatonin versus synthetic melatonin in cancer treatments
}

\author{
Marino B Arnao* and Josefa Hernández-Ruiz \\ Department of Plant Physiology, Faculty of Biology, University of Murcia, Spain
}

\begin{abstract}
Melatonin is a molecule with a wide variety of interesting functions in animals. In mammals, it is synthesized by the pineal gland, and other tissues. This endocrine compound has been studied for use in anti-tumor treatments of various kinds. Melatonin seems to play an important role in multiple stages of tumor development, both in growth/proliferation and in apoptosis and metastasis, and through immunological regulation. While synthetic melatonin is usually used in these studies, this work looks at, an alternative, phytomelatonin, melatonin of plant origin. The interest of this proposal arose from the need to avoid the unwanted by-products present in synthetic melatonin preparations. The substitution of synthetic melatonin by phytomelatonin in medical treatments could also lead to substantial improvements in the results. The application of phytomelatonin in clinical studies is proposed as an objective.
\end{abstract}

\section{Introduction}

Melatonin ( $N$-acetyl-5-methoxytryptamine) is widely known as a biological modulator of circadian rhythms, mood, sleep, body temperature, locomotor activity, food-intake, retina physiology, sexual behavior, seasonal reproduction and immunological system. Added to this, is an excellent antioxidant, at physiological concentrations.

In mammals, melatonin is secreted by the pineal gland into the cerebrospinal liquid and to the bloodstream, maximal levels being reached during the middle of the night. This circadian pattern of melatonin secretion is regulated by the biological clock that resides in mammals within the hypothalamic suprachiasmatic nucleus (SCN) [1]. The SCN is synchronized to the environmental light-dark cycle by the light perceived by the retina. Also, the SCN regulates pineal secretion through a polysynaptic network in the paraventricular nucleus of the hypothalamus [2]. Melatonin liberation occurs when the norepinephrine released by paraventricular nucleus fibers activates the pineal $\beta$-adrenergic receptors, stimulating, through the cyclic AMP, serotonin $N$-acetyltransferase (SNAT) expression in the dark. However, brief exposure to light provokes a decrease in melatonin production because of the degradation of SNAT in the pineal gland [3-5].

Thus, melatonin is of importance as a chronobiological agent, acting as a signal of darkness that provides information to the brain and peripheral organs. It is endogenous synchronizer for both endocrine (i.e. neurotransmissor release) and other physiological rhythms, regulating sleep-wake cycles and synchronizing life activity with seasonal periods and reproductive functions [6-11].

Among other roles, melatonin plays an important part in the regulation of sleep, body temperature, the state of alertness and the degree of concentration or performance, and cortisol rhythms. Melatonin is a sleep initiator for opening the circadian sleep-gate, acting as a sleep regulator. Melatonin adjusts the timing or reinforces oscillators of the central biological clock. Exogenous melatonin administration alters the timing of bodily rhythms, including sleep, where phase delays are observed with the morning administration of melatonin, while phase advances are found after evening administration [12]. Many sleep disorders have been treated with melatonin: delayed sleep phase syndrome, night shift-work sleep disorder, seasonal affective disorder, sleep disorders in the blind and aging, and in pathophysiological disorders of children, with notable improvements in the 'sleep quality'. The most widespread disorder treated with melatonin is jet-lag, a dephasing of the sleep-wake rhythms resulting from trans-oceanic flights [13-15].

Neurological disorders and others have been related to alterations in melatonin oscillations or their receptors, including Alzheimer's and Parkinson's syndrome, glaucoma and macular degeneration, chronic fatigue syndrome, multiple sclerosis, depression, schizophrenia, anxiety, menopause, gastrointestinal- coronary- and cardiac-diseases, food intake pattern and obesity, osteoporosis, etc. Providing information on these particular aspects is beyond the scope of this paper, but relevant papers on the subject and the works cited therein can be consulted [16-32]. Alterations in the expression of melatonin receptors, as well as unexpected changes in the endogenous production of melatonin, have been associated with the emergence of many diseases and disorders listed above. The decrease in melatonin levels has also been associated with susceptibility to the occurrence of certain types of cancer. Melatonin production by the pineal gland is persistent until the age of twenty (after which it declines with age) [33] and it has also been related with disorders because of alterations in day-timing mainly through changes in the sleep/wake cycles.

Since the pioneering works $[34,35]$, which indicated a possible relationship between the light environment and the appearance of mammary tumors, reports have described a relationship between the

*Correspondence to: Marino B Arnao, Department of Plant Physiology, Faculty of Biology, University of Murcia, Spain, Tel: +34-868-883-000; E-mail: marino@um.es

Key words: antioxidant, anti-tumoral, apoptosis, EMS, melatonin, phytomelatonin

Received: July 13, 2018; Accepted: July 27, 2018; Published: July 31, 2018 
pineal gland and breast cancer [36], and also the relationship between low urinary melatonin levels and the occurrence of human breast cancer [37]. Furthermore, many studies have pointed to a high breast cancer incidence in women night-shift workers due to excessive exposure to light at night $[38,39]$. Thus, a continuous reduction in melatonin levels might contribute to the probability of initiation and progression of breast cancer. The possible link of melatonin with cancer risk has been associated with its function as down regulator of the pituitary and gonadal hormones which control mammary gland development, among other factors [40-43]. These same indications regarding the effect of alterations in the sleep-wake cycle and cancer risk have also been studied by reference to the proliferation of colorectal cancer in female nurses [44].

Many other cancers have been associated with low melatonin levels in the bloodstream or have been treated with this indolic molecule to stop or decelerate the growth of cancerous cells $[45,46]$. In general, melatonin might act as an anti-cancerogenic and anti-tumoral agent through several functions. These include the regulation of hormone secretion, its ability to reduce DNA damage by reactive oxygen and nitrogen species (ROS/RNS) as a consequence of its excellent freeradical scavenging properties, the upregulation of antioxidant enzymes, alteration of the expression of growth and differentiation-related genes, and the inhibition, via membrane receptors, of the uptake of fatty acids in hepatoma cells, thus delaying the conversion of linoleic acid into 13-hydroxyoctadecadienoic acid, a mitogenic signaling molecule. It may also reduce the metastatic capacity of tumor cells, inhibit telomerase activity in the same cells, and act on some oncogenesisrelated genes that control the cell cycle and cell defense. Complementary to all these actions, melatonin is an immunomodulator capable of activating lymphocytes and monocytes/macrophages, and, through immunosurveillance, cancer cells can be detected and eliminated, preventing tumor development [45-55]. Figure 1 shows the broad spectrum of actions in which melatonin has been experimented with results generally evaluated positively against cancer.

\section{Cancer and melatonin treatments}

Melatonin has been seen to have onco-static properties in different in vitro and in vivo experimental models of neoplasia. The effects of melatonin are mediated by both receptor-dependent and receptor-independent mechanisms. Melatonin receptors include plasma membrane and nuclear binding sites. Generally, the antitumoral properties of melatonin are observed at pharmacological concentrations, that is, at concentrations clearly superior to the physiological, between micro and millimolar; however, in some tissue's melatonin concentrations may reach these last levels, such as in saliva, gastrointestinal and bile, among others. The effects of melatonin against tumors can be classified as cytostatic and cytotoxic. Thus, cytotoxicity is observed exclusively at high melatonin concentrations, the type of cells and tumor being decisive in its effectiveness. Thus, depending on the cancer cell type responses may differ at low or high melatonin treatment levels. For example, breast cancer cells are sensitive to low (nanomolar) melatonin concentrations, stopping their proliferation, while others have no response. However, high melatonin concentrations may inhibit proliferation, as occurs in colon cancer cells, and in similar way in human prostate cancer cells, among others. Curiously, cytotoxicity is not observed in any type of non-tumoral cell, even at very high melatonin concentrations. This feature means that melatonin can be used against tumors without causing damage to healthy cells [56].

Apoptosis is the main response to high melatonin doses in some cancer cell types. For example, in Ewing's sarcoma cell lines, $1 \mathrm{mM}$ melatonin provokes a clear reduction in cell viability through the induction of cell apoptosis [57]. Reactive oxygen species (ROS) and reactive nitrogen species (RNS), mainly hydrogen peroxide and nitric oxide (NO), form part of the redox network which is a crucial element in the cellular response to stressors. At low levels, ROS/RNS can induce an increase in cell proliferation; while at high levels, they can induce apoptosis. Intracellular levels of ROS/RNS increased early in cells that died by apoptosis, decreased after $48 \mathrm{~h}$ in cells that diminished their proliferation and did not change in non-sensitive cells. Also, cells that died through apoptosis showed decreased GSH levels. The administration of antioxidants prevented melatonin-induced apoptosis, while hydrogen peroxide enhanced it. It seems, therefore, that the induction of apoptosis by high concentrations of melatonin in sensitive cancer cells is related to the increase in ROS levels and, given the early appearance of such a phenomenon, it is likely to be a key factor in melatonin-induced cell death. Also, cells undergoing apoptosis presented decreased expression of antioxidant enzymes. Therefore, antioxidant balance and redox network regulation seems to have a relevant role in these pro-apoptotic responses mediated by melatonin $[56,58]$.

There is much evidence that melatonin mitigates cancer in the initiation, progression and metastasis phases. Many studies have shown that the co-administration of melatonin with chemo- and radiotherapy improves the sensitivity of cancers to inhibition by conventional

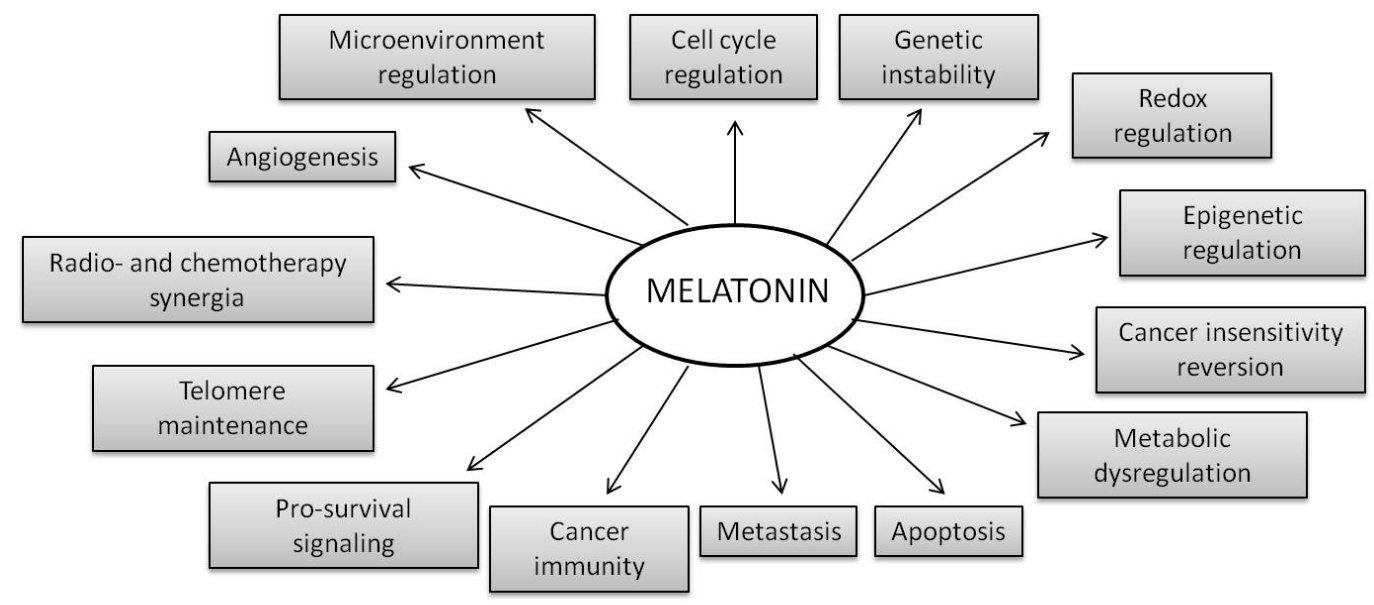

Figure 1. Multiple actions proposed by melatonin interacting with tumors [59]. 
drugs. Thus, melatonin works as a synergistic agent in the killing of cancer cells. Melatonin also inhibits molecular processes associated with metastasis by limiting the entrance of cancer cells into the vascular system and preventing them from the new establishing sites [59]. Chemo- and radiotherapies damage normal tissues. Melatonin mitigates acute damages in normal cells, protecting against cardio-, hepatic and renal toxicity of many drugs. For example, in hematological neoplasms, the combination of melatonin with chemotherapeutic agents promotes survival, enhances the efficacy and immunomodulation and ameliorates toxicity due to chemotherapy. Melatonin combined with radiotherapy promotes the apoptosis of hematological cancer cells while protecting the normal splenocytes, suggesting its selective cytotoxicity to hematological neoplasms [60]. Also, certain plant foods or diet patterns might play a role in the prevention and management of cancer, which has been related to the high content of dietary fibers and various phytochemicals, although controversy still exists regarding this topic [61-63].

\section{Use of phytomelatonin instead of melatonin}

Melatonin and phytomelatonin are the same molecule, "melatonin" referring to melatonin of synthetic or animal origin and "phytomelatonin" to that of plant origin. Previously, melatonin was obtained from animal sources such as cows, but due to the risk of viral infection, synthetic production is often preferred, using a simple and very productive process [64-66].

Since the discovery of melatonin in 1958 by Lerner and co-workers [67], the organic synthesis of melatonin has been significantly improved with the arrival of more productive and economic processes. Synthetic melatonin is generated with yields of over $80 \%$, although many byproducts, i.e., unwanted compounds of the chemical melatonin preparation processes, also appear. Table 1 shows some of the most common of these which are present in the commercially available synthetic melatonin preparations. Most occur at concentrations below $0.5 \%$, although it is difficult to establish the exact concentration due to the different methods and mother materials from which the synthetic melatonin is obtained. These contaminants can be classified according to the synthetic route used $[68,69]$. Thus, in "classic" organic melatonin synthesis from derived-indoles (methoxyindoles, etc.), the contaminants are related to tryptophan, which have also been described in tryptophan supplements. Other contaminants, such as oxidized forms of melatonin or condensation-related products, arise from the instability of melatonin. In other cases, up to 14 contaminants have been described in the organic synthesis of melatonin from phthalimide.

Eosinophilia-myalgia syndrome (EMS) is an incurable and sometimes fatal disease, which first time in 1989 in New Mexico and Minnesota. In 1993, there were 1511 cases associated with EMS

Table 1. Common unwanted by-products in synthetic melatonin preparations

\begin{tabular}{|l|}
\hline $1,2,3,4$-tetrahydro- $\beta$-carboline-3-carboxylic acid \\
\hline 3-(phenylamino)alanine (PAA) \\
\hline 1,1'-ethylidenebis-(tryptophan) (so-called peak E) \\
\hline 2-(3-indolylmethyl)-tryptophan \\
\hline formaldehyde-melatonin \\
\hline formaldehyde-melatonin condensation products \\
\hline 5-hydroxy-tryptamine derivatives \\
\hline 5-methoxy-tryptamine derivatives \\
\hline -acetyl- and diacetyl-indole derivatives \\
\hline 1,3-diphthalimidopropane \\
\hline hydroxy-bromo-propylphthalimide \\
\hline Chloropropylphthalimide \\
\hline
\end{tabular}

and 37 deaths. It has been related to the presence of L-tryptophan derivatives in some poorly produced dietary supplements of tryptophan manufactured by six companies in Japan [70,71]. These are mainly contaminants from the so-called "peak E" and PAA listed in Table 1. These last two contaminants also seem to be related rapeseed oil syndrome in Spain (TOS, Spanish toxic oil syndrome) in 1981, which killed about 900 people and left another 20000 affected [70]. Melatonin has also been reported to induce eosinophilia in patients with cancer [72]. With regard to phthalimide, this widely used chemical is currently subject to multiple toxicological investigations, but there are no conclusive data available. However, the fact that phthalimide is present in toxic compounds such as pesticides and fungicides, suggests that some degree of toxicity is to be expected. Irritation of the eyes, dermatitis through skin contact, and respiratory tract sensitization are the only side effects that have been officially noted: "Chronic Potential Health Effects: no information found at this time. The toxicological properties of this substance have not been fully investigated" [73]. Some studies on possible teratogenic, mutagenic, and genotoxic effects due to similarities with thalidomide and fungicides (folpet, captan) have been suggested. In either case, there is a very small degree of risk involved in taking chemically synthesized melatonin supplements. In the case of phytomelatonin, it's a priori natural origin should rule out any possibility of contamination due to chemical synthesis. Furthermore, phytomelatonin-rich extracts are "accompanied" by a set of other substances including antioxidants, vitamins, simple phenols, flavonoids, carotenoids, and tocopherols, which are known to participate in the beneficial functions that phytomelatonin has in our body [74-79].

The use of phytomelatonin in dietary supplements and in other applications such as cosmetics should be considered, although very few products formulated with phytomelatonin exist commercially. Also, its use as an anti-tumoral effector may be interesting since it would prevent residual synthetic by-products from being incorporated during tumor treatments. Also, the presence in the phytomelatonin-rich extracts of several plant antioxidants such as ascorbic acid, simple phenols, flavonoids, carotenoids, tocopherols, among others, might be relevant for maintaining an appropriate redox balance. Some phytomelatoninrich foods have been checked in some experimental tests, all showing, in general, healthy effect such as an increase in plasma melatonin levels and in antioxidant status. Also, an increase in sleep quality parameters has been observed [80-90].

Phytomelatonin is present in all the plant species studied to date. Generally, low or very low levels (pg to ng/g plant tissues) of phytomelatonin are the common content in most plant tissues. However, in some cases, such as aromatic/medicinal plants, phytomelatonin level are higher [91,92]. At present, only 2-3 manufacturers market phytomelatonin-rich products. One of them, in the USA, presents a formulation in which rice, alfalfa and green alga Chlorella are combined. The presence of Chlorella suggests that the phytomelatonin is mainly obtained by cultivating these green algae in bioreactors, although it is impossible to say whether the process involves enrichment (feeding) with phytomelatonin precursor, L-tryptophan, [93]. Unfortunately, the use of synthetic L-tryptophan - if this is the case - would lead to a higher presence of unwanted synthetic by-products such as those mentioned above. Another aspect to consider when using green alga in cultures is that the presence of cyanotoxins (microcystins, anatoxin-a, dihydroanatoxin-a, epoxyanatoxin-a, cylindrospermopsin, saxitoxin, among others) is common due to contamination by cyanobacteria (blue-green algae). These cyanotoxins present several unwanted effects such as carcinogenicity, hepatotoxicity, neurotoxicity, cytotoxicity and dermatotoxicity. Thus, the detection of many cyanotoxins in some algal 
- Phytomelatonin-rich extracts can be used in cancer experimentation. - Phytomelatonin avoids the presence of unwanted by-products of synthetic melatonin.

- Phytomelatonin-rich extracts are rich in interesting natural compounds such as polyphenols, carotenoids, tocopherols, among others.

- The performance of experimental and clinical trials will be essential to confirm beneficial effects.

- The use of phytomelatonin in other health applications (sleep disorders, neurological dysfunctions, cosmetic, etc.) can be interesting.

Figure 2. Highlights proposed by phytomelatonin related with cancer studies

dietary supplements reinforces the need for a better-quality control concerning the potential risks associated with the consumption of these algal supplements [94-96].

In another product produced in New Zealand, the source of phytomelatonin is freeze-dried Montmorency tart cherry skin extracts. The content in tart cherries is very low, around $14 \mathrm{ng}$ of phytomelatonin/g fruit [97], and so, to obtain interesting phytomelatonin-rich extracts, the concentration protocol would have to be very intensive.

Recently, our research group at the University of Murcia generated phytomelatonin-rich extracts, in which only aromatic/medicinal plants are used to obtain a botanical mixture rich in phytomelatonin through the application of a simple and natural process [98]. A rigorous plant selection protocol and careful management ensure a high phytomelatonin content in the botanical mix and in the plant, extracts generated from it. The formulation and its protocol are being patented, before becoming available to interested companies for commercial exploitation. Also, we are beginning tests in animals to confirm some of the known effects for melatonin and to compare possible benefits with those now associated with synthetic melatonin.

\section{Future perspectives}

The possibility of using phytomelatonin instead of synthetic melatonin in many applications such as dietary supplements and cosmetic products is a reality. Also, phytomelatonin-rich extracts can be used in anti-tumoral treatments. The use of phytomelatonin instead synthetic melatonin will ensure that no unwanted by-products are present in melatonin treatments. Figure 2 shows the most prominent lines of action to be developed with phytomelatonin. At present, we are not aware that any such anti-cancer assays are being carried out with phytomelatonin, but we believe that they would provide interesting results. Also, it is necessary to ensure that phytomelatonin-rich products are free of pesticides or other contaminants such as cyanotoxins. Another important step would be to carry out a series of clinical trials to compare the physiological effects of phytomelatonin-rich products with those obtained using synthetic melatonin.

\section{References}

1. Klein D, Moore R (1979) Pineal N-acetyltransferase and hydroxyindole-Omethyltransferase: control by the retinohypothalamic tract and the suprachiasmatic nucleus. Brain Res 174: 245-262. [Crossref]

2. Buijs R, Hermes M, Kalsbeek A (1988) The suprachiasmatic nucleus-paraventricular nucleus interactions: a bridge to the neuroendocrine and autonomic nervous system. Progr Brain Res 119: 365-382. [Crossref]

3. Klein D, Weller J, Moore R (1971) Melatonin metabolism: neural regulation of pineal serotonin acetyl coenzyme A N-acetyltransferase activity. Proc Nat Ac Sci USA 68: 3107-3110. [Crossref]
4. Krause DN, Dubocovich ML (1990) Regulatory sites in the melatonin system of mammals. Trends Neurosci 13: 464-470. [Crossref]

5. Maronde E, Stehle JH (2007) The mammalian pineal gland: known facts, unknown facets. Trends Endocr Metabol 18: 142-149.

6. Reiter RJ (1993) The melatonin rhythm: both a clock and a calendar. Experientia 49: 654-664. [Crossref]

7. Stehle JH, von Gall C, Korf HW (2003) Melatonin: a clock-output, a clock-input. $J$ Neuroendocrinol 15: 383-389. [Crossref]

8. Saper CB, Scammell TE, Lu J (2005) Hypothalamic regulation of sleep and circadian rhythms. Nature 437: 1257-1263. [Crossref]

9. Fuller PM, Gooley JJ, Saper CB (2006) Neurobiology of the sleep-wake cycle: sleep architecture, circadian regulation, and regulatory feedback. J Biol Rhyt 21: 482-493.

10. Jan JE, Reiter RJ, Wasdell MB, Bax M (2009) The role of the thalamus in sleep, pineal melatonin production, and circadian rhythm sleep disorders. $J$ Pineal Res 46: 1-7. [Crossref]

11. Reppert SM, Weaver DR (2002) Coordination of circadian timing in mammals. Nature 418: 935-941. [Crossref]

12. Lewy A, Ahmed S, Jackson J, Sack R (1992) Melatonin shifts human circadian rhythms according to a phase-response curve. Chronobiol Int 9: 380-392. [Crossref]

13. Waterhouse J, Reilly T, Atkinson G (1997) Jet-lag. Lancet 350: 1611-1616. [Crossref]

14. Takahashi T, Sasaki M, Itoh H, Ozone M, Yamadera W, et al. (2000) Effect of $3 \mathrm{mg}$ melatonin on jet lag syndrome in an 8-h eastward flight. Psychiatry Clin Neurosci 54: 377-378. [Crossref]

15. Herxheimer A (2005) Jet lag. Clin Evid: 2178-2183. [Crossref]

16. Hardeland R (2012) Melatonin in aging and disease. Multiple consequences of reduced secretion, options and limits of treatment. Aging Dis 3: 194-225. [Crossref]

17. Pandi-Perumal SR, Trakht I, Srinivasan V, Spence DW, Maestroni GJM, et al. (2008) Physiological effects of melatonin: role of melatonin receptors and signal transduction pathways. Progr Neurobiol 85: 335-353. [Crossref]

18. Srinivasan V, Pandi-Perumal SR, Maestroni GJM, Esquifino AI, Hardeland R, et al (2005) Role of melatonin in neurodegenerative diseases. Neurotoxicol Res 7: 293-318. [Crossref]

19. Wilhelmsen M, Amirian I, Reiter RJ, Rosenberg J, Gögenur I (2011) Analgesic effects of melatonin: a review of current evidence from experimental and clinical studies. $J$ Pineal Res 51: 270-277. [Crossref]

20. Claustrat B, Brun J, Chazot G (2005) The basic physiology and pathophysiology of melatonin. Sleep Med Rev 9: 11-24. [Crossref]

21. Poeggeler B (2005) Melatonin, aging, and age-related diseases: perspectives for prevention, intervention, and therapy. Endocrine 27: 201-212. [Crossref]

22. Hardeland R, Madrid JA, Tan DX, Reiter RJ (2012) Melatonin, the circadian multioscillator system and health: the need for detailed analysis of peripheral melatonin signal. J Pineal Res 52: 139-166. [Crossref]

23. Reiter RJ (2003) Melatonin: clinical relevance. Best Pract Res Clin Endocrinol Metab 17: 273-285. [Crossref]

24. Hussein MR, Ahmed OG, Hassan AF, Ahmed MA (2007) Intake of melatonin is associated with amelioration of physiological changes, both metabolic and morphological pathologies with obesity: an animal model. Int J Exp Pathol 88: 19-29. [Crossref] 
25. Witt-Enderby PA, Radio NM, Doctor JS, Davies VL (2006) Therapeutics treatments potentially mediated by melatonin receptors: potential clinics uses in the prevention of osteoporosis, cancer and as an adjuvant therapy. J Pineal Res 41: 297-305. [Crossref]

26. Wu YH, Swaab DF (2005) The human pineal gland and melatonin in aging and Alzheimer's disease. J Pineal Res 38: 145-152. [Crossref]

27. Agorastos A, Huber CG (2011) The role of melatonin in glaucoma: implications concerning pathophysiological relevance and therapeutic potential. J Pineal Res 50: 1-7. [Crossref]

28. Maldonado MD, Murillo-Cabezas F, Terrón MP, Flores LJ, Tan DX, et al. (2007) The potential of melatonin in reducing morbidity-mortality after craniocerebral trauma. $J$ Pineal Res 42: 1-11. [Crossref]

29. Willis GL, Robertson AD (2004) Recovery of experimental Parkinson's disease with melatonin analogues ML-23 and S-20928 in a chronic, bilateral 6-OHDA model: a new mechanism involving antagonism of the melatonin receptor. Pharmacol Biochem Behav 79: 413-429. [Crossref]

30. Reiter RJ, Burkhardt S, Cabrera J, Garcia JJ (2002) Beneficial neurobiological effects of melatonin under conditions of increased oxidative stress. Curr Med Chem-Central Nervous System Agents 2: 45-58.

31. Alghamdi BS (2018) The neuroprotective role of melatonin in neurological disorders. J Neurosci Res 96: 1136-1149. [Crossref]

32. Osier N, McGreevy E, Pham L, Puccio A, Ren D, et al. (2018) Melatonin as a Therapy for Traumatic Brain Injury: A Review of Published Evidence. Int J Mol Sci 19. [Crossref]

33. Humbert W, Pevet P (1994) The decrease of pineal melatonin production with age. Causes and consequences. Ann N Y Acad Sci 719: 43-63. [Crossref]

34. Hamilton T (1969) Influence of environmental light and melatonin upon mammary tumour induction. Br J Surg 56: 764-766. [Crossref]

35. Taylor PJ, Pocock SJ (1972) Mortality of shift and day workers 1956-68. Br J Ind Med 29: 201-207. [Crossref]

36. Cohen M, Lippman M, Chabner B (1978) Role of pineal gland in aetiology and treatment of breast cancer. Lancet 2: 814-816. [Crossref]

37. Bartsch C, Bartsch H, Jain AK, Laumas KR, Wetterberg L (1981) Urinary melatonin levels in human breast cancer patients. J Neural Transm 52: 281-294. [Crossref]

38. Tamarkin L, Danforth D, Lichter A, DeMoss E, Cohen M, et al. (1982) Decreased nocturnal plasma melatonin peak in patients with estrogen receptor positive breast cancer. Science 216: 1003-1005.

39. Hansen J (2001) Increased breast cancer risk among women who work predominantly at night. Epidemiology 12: 74-77. [Crossref]

40. Davis S, Mirick DK, Stevens RG (2001) Night shift work, light at night, and risk of breast cancer. $J$ Natl Cancer Inst 93: 1557-1562. [Crossref]

41. Knutsson A (2003) Health disorders of shift workers. Occup Med (Lond) 53: 103-108. [Crossref]

42. Cos S, Sánchez-Barceló EJ (2000) Melatonin and mammary pathological growth Front Neuroendocrinol 21: 133-170. [Crossref]

43. Kamdar BB, Tergas A, Mateen FJ, Bhayani NH, Oh J (2013) Night-shift work and risk of breast cancer: a systematic review and meta-analysis. Breast Cancer Res Treat 138: 291-301.

44. Schernhammer ES, Laden F, Speizer FE, Willett WC, Hunter DJ, et al. (2003) Nightshift work and risk of colorectal cancer in the nurses' health study. $J$ Natl Cancer Inst 95: 825-828. [Crossref]

45. Blask DE, Sauer LA, Dauchy RT (2002) Melatonin as a chronobiotic/anticancer agent: cellular, biochemical and molecular mechanisms of action and their implications for circadian-based cancer therapy. Curr Top Med Chem 2: 113-132.

46. Reiter RJ (2004) Mechanisms of cancer inhibition by melatonin. J Pineal Res 37: $213-$ 214. [Crossref]

47. Di Bella G, Mascia F, Gualano L, Di Bella L (2013) Melatonin anticancer effects: review. Int J Mol Sci 14: 2410-2430. [Crossref]

48. Anisimov VN, Popovich IG, Zabezhinski MA, Anisimov SV, Vesnushkin GM, et al. (2006) Melatonin as antioxidant, geroprotector and anticarcinogen. Biochim Biophys Acta 1757: 573-589. [Crossref]

49. Miller SC, Pandi-Perumal SR, Esquifino AI, Cardinali DP, Maestroni GJM (2006) The role of melatonin in inmmuno-enhancement: potential application in cancer. Int $J$ Exp Pathol 87: 81-87.
50. Rodríguez C, Martin V, Herrera F, García-Santos G, Rodríguez-Blanco J, et al. (2013) Mechanisms involved in the pro-apoptotic effect of melatonin in cancer cells. Int $\mathrm{J} \mathrm{Mol}$ Sci 14: 6597-6613.

51. Seely D, Wu P, Fritz H, Kennedy DA, Tsui T, et al. (2012) Melatonin as adjuvant cancer care with and without chemotherapy: A systematic review and meta-analysis of randomized trials. Integr Cancer Ther. 11: 293-303.

52. Rodriguez C1, Mayo JC, Sainz RM, Antolín I, Herrera F, et al. (2004) Regulation of antioxidant enzymes: a significant role for melatonin. J Pineal Res 36: 1-9. [Crossref]

53. Tomás-Zapico C, Coto-Montes A (2005) A proposed mechanism to explain the stimulatory effect of melatonin on antioxidative enzymes. J Pineal Res 39: 99-104.

54. Carrillo-Vico A, Guerrero JM, Lardone PJ, Reiter RJ (2005) A review of the multiple actions of melatonin on the immune system. Endocrine 27: 189-200. [Crossref]

55. Jung-Hynes B, Reiter RJ, Ahmad N (2010) Sirtuins, melatonin and circadian rhythms: building a bridge between aging and cancer. J Pineal Res 48: 9-19. [Crossref]

56. Rodriguez C, Martín V, Herrera F, García-Santos G, Rodriguez-Blanco J, et al. (2013) Mechanisms involved in the pro-apoptotic effect of melatonin in cancer cells. Int J Mol Sci 14: 6597-6613. [Crossref]

57. Casado-Zapico S, Martín V, García-Santos G, Rodríguez-Blanco J, Sánchez-Sánchez $\mathrm{AM}$, et al. (2011) Regulation of the expression of death receptors and their ligands by melatonin in haematological cancer cell lines and in leukaemia cells from patients. $J$ Pineal Res 50: 345-355. [Crossref]

58. Matés JM, Segura JA, Alonso FJ, Márquez J (2008) Intracellular redox status and oxidative stress: implications for cell proliferation, apoptosis, and carcinogenesis. Arch Toxic 82: 273-299. [Crossref]

59. Reiter RJ, Rosales-Corral SA, Tan DX, Acuna-Castroviejo D, Qin L, et al. (2017) Melatonin, a Full Service Anti-Cancer Agent: Inhibition of Initiation, Progression and Metastasis. Int J Mol Sci: 18. [Crossref]

60. Li T, Yang Z, Jiang S, Di W, Ma Z, et al. (2017) Melatonin: does it have utility in the treatment of haematological neoplasms? Br J Pharmacol. [Crossref]

61. Tao J, Li Y, Li S, Li HB (2018) Plant foods for the prevention and management of colon cancer. $J$ Funct Foods 42: 95-110.

62. Salem AA, Mackenzie GG (2018) Pancreatic cancer: A critical review of dietary risk Nutr Res 52: 1-13. [Crossref]

63. Hari S, Vasudevan V, Kasibhotla S, Reddy D, Venkatappa M, et al. (2016) Antiinflammatory dietary supplements in the chemoprevention of oral cancer. Cancer Res Front 2: 380-395.

64. Hugel HM, Kennaway DJ (1995) Synthesis and chemistry of melatonin and of related compounds. A review. Org Prep Proc Int 27: 1-31.

65. Prabhakar C, Vasanth-Kumar N, Ravikanth-Reddy M, Sarma RM, Om-Reddy G (1999) Process research and development of melatonin. Org Proc Res Dev 3: 155-160.

66. Thomson DW, Commeureuc AGJ, Berlin S, Murphy JA (2003) Efficient route to the pineal hormone melatonin by radical-based indole synthesis. Synth Comm 33: 36313641.

67. Lerner AB, Case JD, Takahashi Y, Lee TH, Mori W (1958) Isolation of melatonin, a pineal factor that lightens melanocytes. J Am Chem Soc 80: 2587.

68. Williamson BL, Tomlinson AJ, Naylor S, Gleich GJ (1997) Contaminants in commercial preparations of melatonin. Mayo Clin Proc 72: 1094-1095. [Crossref]

69. Naylor S, Johnson KL, Williamson BL, Klarskov K, Gleich GJ (1999) Structural characterization of contaminants in commercial preparations of melatonin by on-line HPLC-electrospray ionization-tandem mass spectrometry. Adv Exp Med Biol 467: 769777. [Crossref]

70. Mayeno AN, Gleich GJ (1994) The eosinophilia-myalgia syndrome: lessons from Germany. Mayo Clin Proc 69: 702-704. [Crossref]

71. Cerezo AB, Leal A, Alvarez-Fernández MA, Hornedo-Ortega R, Roncoso AM, et al. (2016) Quality control and determination of melatonin in food supplements. $J$ Food Comp Anal 45: 80-86.

72. Lissoni P, Barni S, Tancini G, Rovelli F, Ardizzoia A, et al. (1993) A study of the mechanisms involved in the immunostimulatory action of the pineal hormone in cancer patients. Oncology 50: 399-402. [Crossref]

73. OECD-Organisation for Economic Co-operation \& Development (2006) Initial assessment report on phthalimide. Screening Information DataSet (SIDS). SIAM 20 Paris, France: ID-85-41-6. 
74. Reiter RJ, Mayo JC, Tan DX, Sainz RM, Alatorre-Jimenez M, et al. (2016) Melatonin as an antioxidant: under promises but over delivers. J Pineal Res 61: 253-278. [Crossref]

75. Shahidi F, Ambigaipalan P (2015) Phenolics and polyphenolics in foods, beverages and spices: Antioxidant activity and health effects. A review. J Funct Foods 18: 820-897.

76. Pisoschi AM, Pop A (2015) The role of antioxidants in the chemistry of oxidative stress: A review. Eur J Med Chem 97: 55-74. [Crossref]

77. Oroian M, Escriche I (2015) Antioxidants: Characterization, natural sources, extraction and analysis. Food Res Int 74: 10-36. [Crossref]

78. Kaulmann A, Bohn T (2014) Carotenoids, inflammation, and oxidative stress: implications of cellular signaling pathways and relation to chronic disease prevention. Nutr Res 34: 907-929. [Crossref]

79. Espín JC, García-Conesa MT, Tomás-Barberán FA (2007) Nutraceuticals: facts and fiction. Phytochemistry 68: 2986-3008. [Crossref]

80. Tan DX, Reiter RJ, Manchester LC (2005) Melatonin in walnuts: influence on levels of melatonin and total antioxidant capacity of blood. Nutrition 21: 920-924. [Crossref]

81. Reiter RJ, Tan DX, Manchester LC, Simopoulos AP, Maldonado MD, et al. (2007) Melatonin in edible plants (phytomelatonin): identification, concentrations, bioavailability and proposed functions. World Rev Nutr Diet 97: 211-230. [Crossref]

82. Aguilera Y, Rebollo-Hernanz M, Herrera T, Cayuelas LT, Rodriguez-Rodriguez P, et al. (2016) Intake of bean sprouts influences melatonin and antioxidant capacity biomarker levels in rats. Food Funct 7: 1438-1445. [Crossref]

83. Gonzalez-Flores D, Gamero E, Garrido M, Ramirez R, Moreno D, et al. (2012) Urinary 6-sulfatoxymelatonin and total antioxidant capacity increase after the intake of a grape juice cv. Tempranillo stabilized with HHP. Food Funct 3: 34-39. [Crossref]

84. Gonzalez-Flores D, Velardo B, Garrido M, González-Gómez D, Lozano M, et al. (2011) Ingestion of Japanese plums (Prunus salicina Lindl. cv. Crimson Globe) increases the urinary 6-sulfatoxymelatonin and total antioxidant capacity levels in young, middleaged and elderly humans: nutritional and functional characterization of their content. $J$ Food Nutr Res 50: 229-236.

85. Garrido M, Paredes SD, Cubero J, Lozano M, Toribio-Delgado AF, et al. (2010) Jerte valley cherry-enriched diets improve nocturnal rest and increase 6-sulfatoxymelatonin and total antioxidant capacity in the urine of middle-aged and elderly humans. $J$ Gerontol A: Biol Sci Med Sci 65: 909-914. [Crossref]

86. Sae-Teaw M, Johns J, Johns NP, Subongkot S (2013) Serum melatonin levels and antioxidant capacities after consumption of pineapple, orange, or banana by healthy male volunteers. J Pineal Res 55: 58-64. [Crossref]
87. Johns NP, Johns J, Porasupthana S, Plaimee P, Sae-Teaw M (2016) Dietary intake of melatonin from tropical fruit altered urinary excretion of 6-sulfatoxymelatonin in healthy volunteers. J Agr Food Chem 61: 913-919. [Crossref]

88. Garrido M, Espino J, González-Gómez D, Lozano M, Cubero J, et al. (2009) A nutraceutical product based on Jerte Valley cherries improves sleep and augments the antioxidant status in humans. Eur eJ Clin Nutr Metab 4: e321-323.

89. Maldonado MD, Calvo JR (2010) The perception that beer improves sleep onset might be a motivation for some to drink heavily. Is it only melatonin that matters? Reply to Dr. Molfino Clin Nutr 29: 273-274.

90. Maldonado MD, Moreno H, Calvo JR (2009) Melatonin present in beer contributes to increase the levels of melatonin and antioxidant capacity of the human serum. Clin Nutr 28: 188-191. [Crossref]

91. Arnao MB (2014) Phytomelatonin: discovery, content, and role in plants. Adv Bot e815769

92. Arnao MB, Hernández-Ruiz J (2015) Functions of melatonin in plants: a review. $J$ Pineal Res 59: 133-150. [Crossref]

93. Marioni F, Bertoli A, Pistelli L (2008) A straightforward procedure to biosynthesise melatonin using freshly chopped Achillea millefolium L. as reagent. Phytochem Lett 1: $107-110$.

94. Roy-Lachapelle A, Solliec M, Bouchard MF, Sauvé S (2017) Detection of Cyanotoxins in Algae Dietary Supplements. Toxins (Basel): 9. [Crossref]

95. Görs M, Schumann R, Hepperle D, Karsten U (2010) Quality analysis of commercial Chlorella products used as dietary supplement in human nutrition. J Appl Phycol 22: 265-276.

96. Campos A, Araújo P, Pinheiro C, Azevedo J, Osório H, et al. (2013) Effects on growth, antioxidant enzyme activity and levels of extracellular proteins in the green alga Chlorella vulgaris exposed to crude cyanobacterial extracts and pure microcystin and cylindrospermopsin. Ecotoxic Environm Saf 94: 45-53. [Crossref]

97. Burkhardt S, Tan DX, Manchester LC, Hardeland R, Reiter RJ (2001) Detection and quantification of the antioxidant melatonin in Montmorency and Balaton tart cherries (Prunus cerasus). J Agric Food Chem 49: 4898-4902. [Crossref]

98. Arnao MB, Hernández-Ruiz J (2018) The Potential of Phytomelatonin as a Nutraceutical. Molecules 23. [Crossref]

Copyright: (C2018 Arnao MB. This is an open-access article distributed under the terms of the Creative Commons Attribution License, which permits unrestricted use, distribution, and reproduction in any medium, provided the original author and source are credited. 